\title{
Rabies Encephalitis Mimicking the Electrophysiological Pattern of Brain Death
}

Sir,

In a recently published paper [1] the authors claim that an otherwise unequivocable diagnosis of brain death could only be ruled out by multimodalityevoked potentials, magnetic resonance imaging, and autopsy. This is not the case.

To my knowledge, all countries worldwide, which accept the concept of brain death or brainstem death, require the demonstration of apnea as part of the clinical investigation [2]. This, however, was not

performed by Hantson et al. [1]. To use the term 'brain death' in this context is grossly misleading. An isolated flat EEG can never be regarded as proof of brain death; it is only able to confirm it, provided that all other requirements are previously fulfilled.

Therefore, in order not to obscure a valid concept or to shed doubt on it, every reader of this article should be aware that brain death was not diagnosed according to contemporary standards.

P. Hantson

Departement de soins intensifs

Clinique de St-Luc, Brussels, Belgium

\section{Reply}

We entirely agree with the comments made by Dr Lang. The reason for which the apnea test was not performed in the present case [1] was that the patient was hypoxemic at this time, due to a lower respiratory tract

infection. The apnea test cannot be interpreted in this setting because oxygen saturation is decreasing rapidly or severe cardiac arrhythmias may occur before the absence of spontaneous breathing could be assessed.

\section{References}

1 Hantson P, Guerit JM, de Tourtchaninoff M, De Coninck B, Mahieu P, Dooms G, Aubert-Tulkens G, Brucher JM: Rabies encephalitis mimicking the electrophysiological pattern of brain death: A case report. Eur Neurol 1993;33: 212-217.

2 Earl Walker A: Cerebral Death, ed 3. Baltimore, Urban \& Schwarzenberg, 1985, p 185. 